\title{
The Cultural Environment of Popular Music Discourses in Contemporary Ghana: A Media and Communication Approach
}

\author{
Eugene Agbasi Adjoteye \\ Department of Communications and General Studies, Methodist University College Ghana \\ eadjoteye@mucg.edu.g
}

\begin{abstract}
The field of popular music is important within the cultural matrix of contemporary Ghana. This paper posits the cultural environment of contemporary music discourses in Ghana as a relevant and significant terrain of media and communication worthy of research in Africa. The paper also sets off the relationship between popular music discourses and micro-identity formation in Ghana and subsequently sets off the nexus between the systemic world and the life world of contemporary Ghanaian quotidian sphere. The first part discusses the terrain of contemporary music discourses in Ghana, whilst the second part treats the emerging issues in terms of popular music discursive functionality and dysfunctionality within the interstices of the Ghanaian cultural environment.
\end{abstract}

Keywords

cultural environment; microidentity formation; discursive formation; social change

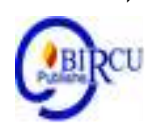

\section{Introduction}

The field of popular music is important in the political, psycho-social, economic and communication relations of Ghana within the new global order of communication processes. The proliferation of new information and communication technology, namely internet, smart phones, Ipads, MP3s, DVDs, fibre optics, satellite and so on has indeed made an impact on popular culture studies in Ghana. It is my contention that it is possible to analyze social change, new psychological perceptions, fathom the nuances of historical and cultural changes of the Ghanaian societal landscape by the holistic study of popular music discourses including its cultural environment.

It is, therefore, the overriding intention of this paper to assert the cultural environment of contemporary popular music discourses in Ghana as an authentic area of media and communication worthy of research in Ghana. In so doing, I intend to set off the individual and social dimensions of its functions and the communication relationships that exist between the systemic world of popular music and the traditional 'gemeinschaft' life world.

The paper will, again, discuss the functionality/ dysfunctionality of contemporary popular music discourses and how they impinge on the cultural environment of popular music. The relationship between popular music discourses and micro-identity formation especially amongst the youth in Ghana within the context of genre development will also be discussed.

John Collins in his article 'From Osibisaba through Highlife to hiplife 2' which appeared in 'The Spectator' on October 27, 2007 p12 gives a historical overview of what corpora of music to include in terms of popular music discourses in Ghana. He stressed inter alia, "Despite the collapse of live entertainment during the seventies and eighties, three musical genres have emerged. One is related to techno -pop styles (like disco and rap). The second is local church music, and the third is 'folkorised' performance 
encouraged by tourism". These musical genres have recently emerged with artistes like Sarkodie, Ofori Amponsah, Kofi B, Nana Boro, Black Rasta, Becca, Kwaw Kesse, Dasebre Dwamena, Shasha Marley, Shatta Wale, Stonebwoy, M.anifest, Gasmilla, Okyeame Kwame, Fuse ODG, Samini, Daddy Lumba, Obra, Owuraku Mickey, Mzbel, Tic Tac, Tinny, Sidney, E.L and so on. Most of these artistes represent "the musical vogue known as 'hiplife', which is a combination of indigenous Ghanaian highlife and western cultural elements and is much appealing and popular to the youth..." ( Akenoo, M (January 5, 2008 p11).

\section{Review of Literatures}

\section{The Terrain of Contemporary Popular Music Discourses in Ghana}

Popular music has been defined by Denisoff (1975) quoted by Burnett (1990, p.52) as: "... the sum total of those taste units, social groups and musical genres which coalesce along certain tastes preference similarities in a given space and time". Clearly, what constitutes popular music in Ghana can be quantified, this is reflected in the sales of a particular cd, dvd, or internet download of a particular Ghanaian musician. The popularity of his or her song may, also, be indicated by the amount of air-time and air-space given him or her on the programming of the various FM stations and TV stations, and the callertunes on the various mobile phone networks, their use on Ipads, MP3 players and so on. As a point of fact, the accessibility of popular music may have been impaired without the development of communication technology of broadcasting- both radio (which can be accessed on at least every mobile phone in Ghana) and tv and information and communication technology.

The popularity of a specific popular music may differ from country to country or even from continent to continent. Obviously, geographical space is important in the delineation of what is popular. The esoteric audience addressed may also be different from society to society. What is mutual to all the geographical spaces in terms of popular culture is the fact that "the youth" are the paramount sociological categories and "taste units" addressed. Indeed, "Youth tastes are not monolithic, they are shaped and influenced by numerous social forces around them, ranging from marital status, education, geographical location" (Reisman, D. (1950, p.359).

The consumption of popular music in Ghana may be the space where the systemic forces meet the life world for meaning and communication. The systemic forces in Ghana refer to the commercial, industrial mechanisms for producing, distributing and marketing the music of a particular musician. In Ghana in the 1960s there were a variety of labels, for example, HMV, Queenophone, Skanophone, Essibons, Decca, Parlophone, Polygram/Philips. In the 1980s and 1990s, some of the corporate production studios behind music production in Ghana were Faisal Helwani's Bokoor 'ministudio', Noble House Productions, and Ghana Films. We can now talk about Pat Thomas music and video production, Jehovah Nissi Studio, Easy Way production, Cebex production and Despite Music studio as some of the production presence which address privatized consumption in contemporary Ghana. In this respect, popular music becomes a putative means for unifying the private domain in a new order of experience. When one listens to a particular cd or popular music piece he thus listens to it in the context of imaginary others.

In Ghana, privatized use of popular music has fragmented the consumption of music in various ways. This can be likened to the effects of the book club and the introduction of new printing technology in creating a privatized reading public in Europe in the c19th. We can, therefore, say at a level that individualism characterizes the use of popular music in 
Ghana. However, in the village sphere, for instance, we can find instances of group culture group culture that sustains the traditional "gemeinschaft" system. It is not uncommon to find a youth group in a Ghanaian village setting listening en masse to unitary content of popular music under a tree. They could travel en masse to a performance by a concert party or popular music band or a "spinning group" in a nearby town and return to the village in the same profile. The centrality of maintaining micro-identities can, therefore, not be underestimated.

Further, on the dance floor palpable social contacts are made that cross traditional social boundaries, for example, the son of a chief or lecturer and the son of a labourer, or rich and poor or the educated and uneducated. These social relations are fostered at dance plazas, discos, youth camps, school fan fares, campus homecomings /school reunions, funeral grounds, soirees, carnivals and so on. It is to be expected that often youth discourses are directed towards questioning traditional values. Among the discursive mechanisms (which fall within the domain of kinesics and artifactics) often marshaled are mode of dressing ('I am aware', 'Otto Pfister'), hair cut (moon walk, three steps, grace jones ,Tokyo joe, mohawk) mode of speaking, handshake, mode of walking, mode of dancing (Azonto), the frequent use of pidgin English, and varieties of code-switching.

Discourses on popular music among the youth in Ghana may, therefore, be seen as channels of interpersonal communication. In sharing the common admiration of popular music or hit performers, a mythology of social equality is purveyed and this may, in some respects, reduce any life world conflicts that may arise among them. At this level, intersubjective and face-to-face communication may help inspire meaning, create youth solidarities and identities.

Clearly, it must be mentioned that socialization processes through the consumption of popular music in Ghana differ from the traditional and orthodox systems ,namely, the church, the family, the school, the sphere of sacred puberty rites like Dipo (among the GaAdangmes). The communication processes within these spheres are clearly different from the sphere of the peer group within the context of their popular music consumption. The reason why the youth may turn to the peer group and popular music activities is probably to fill an intense psychological and socio-cultural vacuum that may not exist in the conventional public sphere like the church or the school. These spheres may not be dynamic in their trappings to cope with radical modern social developments occurring within the global sphere.

The redundant nature of popular music (cf. Fiske, J. (2010) addresses itself to the sub-culture of the youth who may desire new social, communication and psychological challenges. The contemporary popular music genre can be identifiable for meaningful discourse among the youth.

Moreover, it is the pressure of conformity with a particular youth group that probably impels an individual Ghanaian youth to turn to a particular type of music. He or she might learn from the medium of popular music what the group expects and this may enable him or her identify with the group by sharing a common perspective for discourse. This is clearly seen in the rasta-hair style and the swagger mode of walking of most reggae music lovers, and their imitative patois within the Ghanaian socio-cultural milieux.

Further, Reisman, D. (1950) in excavating the American society of the 1950s sets off two polar attitudes among the youth towards popular culture - a majority category and a minority category. The majority category accepts the adult picture of the youth uncritically and the minority category encapsulates socially rebellious attitudes. It is, therefore, clear that even among the sub-category of youth culture there may be sub-cultures. In Ghana, this may perhaps be exemplified in the differences that exist in youth cultures that are 
palpable in the urban metropolis especially in the slums and ghettoes and that of the rural areas. The urban category may fall within the minority category as they may be potentially and relatively more rebellious than the rural youth in accepting the zeitgeist of the adult population.

Popular music may thus be overtly used in Ghana to create a feeling of cultural identity among the youth. Fans of a particular musician and of a particular music genre may appropriate images that become part of their group sub-cultural identities. The use of epithets and subriquets may be a mode of expressing these identities. It is not uncommon to find young boys in Ghana calling themselves and each other "abodam" a phraseology from the repertoire of a Ghanaian popular musician Kwaw Kesse or identifying themselves with the "Shatta movement" (clearly, resonating the influence of the Ghanaian musician, Shatta Wale). This constitutes a communication feedback that could be synergistically beneficial to the addresser, addressee and the socio-cultural framework within which the communication process takes place.

Popular music becomes pro-social in so far as it conforms to the normative expectations and the ethical values of the life world of the Ghanaian adult society. AsanteDarko \& Geest (1983) give copious examples of how the texts of highlife songs are used for phatic communion (interpersonal communication) among friends and acquaintances. They also provide examples of how names of successful songs are given to cloth designs. These discursive formations are in tandem with the traditional Ghanaian life world. For example, the Adinkra cloth designs set off a cosmological universe sui generis to the Ghanaian cultural environment. They are apparently as important as prosaic inscriptions on mammy-trucks (tro-tros) that add spice to the daily (proverbial and aphoristic) discourses of Ghanaians.

\section{Discussion}

\section{Emerging Issues}

It is pertinent to note from the above that popular music discourses are functional within the interstices of the Ghanaian cultural environment. We can justify this functionality in terms of its information, entertainment, mobilization, personal identity, social integration dimensions (McQuail, 2010).

At the level of information, we can talk about popular music content being used in advertisements and public statements about the effects of cocoa smuggling on the national economy, effects of diseases like AIDS, H1N1 Flu, malaria, cholera, lassa fever, dengue fever, ebola and so on. The lyrics of popular songs, were, thus, used to inform the citizenry about their material and mundane conditions.

Popular music has, thus, been used for mobilization purposes. Traditionally, music had been used for societal objectives in the public sphere e.g. war, politics, economic development, community work, religious purposes and so on (Nketia, J.H. 1986).

During the 1996, 2004, 2008 and 2012, 2016 electioneering campaigns in Ghana, popular music was used as a composite instrument for attracting people to political rallies both in the rural and the urban areas. The song "Onaapo" (composed by Nacee) used by the National Democratic Congress as a conflictual song to garner support for its candidate was utilized by the National Patriotic Party to unite its supporters in the delirium of their victory in the 2016 Ghana Elections.

By also expressing a dominant culture or mythology and the existence of a subculture (like a formidable youth culture) popular music discourses serve as a channel for 
maintaining social stability. This is, also, poignantly set off in its recognition of new cultural developments and the maintenance of a commonality of values.

The stability and integration function of popular music is, further, seen in its entertainment aspects. By providing amusement, diversion and so on popular music reduces social tension, people are diverted from the poverty of their circumstances, their sexuality is aroused, their pent up emotions are released and so on.

On the micro dimension, we can, further, talk about individuals listening to popular music to lift psycho-social stresses off their systems. Individuals seek advice as regards perturbed emotional and psychological states. It is not uncommon to find Ghanaians quoting proverbs and aphorisms learnt from songs in order to solve crisis situations and the ennui that confronts them.

A person can, therefore, find reinforcement of personal identity and personal values by listening to popular music. A person looking for models of behavior can find it in the lyrics of popular music, in which case proverbial or mythological characters are set off. The person can also identify with "the valued other" this could be the musician or composer of the song. Indeed, popular music enables a person gain insight into himself or herself, this is the cognitive aspect of music. In this connection, a person can reflect his or her identity, learn how to express his or her feelings and develop his or her ideals (cf. Fornas, J. (1990) ). Here the relationship between cultural form (music) and psychic structure is set off.

Interpretation of situations in the life world as already discussed above can also be crucial. In this wise, the mediating role of popular music discourses can not be underestimated this is especially important for socializing the youth.

Further, popular music can be used for consensus building (centripetal functionality). Musicians can set the agenda for social equality and unity. The lyrics of popular music can thus "triangulate" the various tribes in Africa for purposes of nation building. Bob Marley's song "Zimbabwe" which was sung at the independence of that country is an important example in this regard.

This brings us to the integration dimension of media and communication. Through popular music discourses the citizenry can be enlightened about the circumstances of others, for example, the oppressed, the blind, the lame, the orphans, and generally, the grief-stricken. This can lead to social empathy and identification. This can be reinforced in how popular music forms the basis for conversation and social interaction among complete strangers, peers and so on. In this respect, interpersonal communication as well as intertribal communication could be enhanced for developmental purposes.

Furthemore, the political elite in the Ghanaian contemporary society only by constitutional means regulate music such that music de rigueur must eschew profanity or risqué lyrics that may set off a particular ethnic group as de trop as was the case with the lyrics of 'Troboudom', A.B Crentsil's song' Moses' or Senior Eddie Donkor's song that talked about the Ewe tribe as 'Number Nine' (meaning de trop) in the 1990s. They caused the same stir as Julius Malema's song 'Shoot the Boer' did in South Africa. Again the charging of three Kenyan musicians, namely, Kamande Wa Kioi, Muiga Wa Njoroge and John DeMathew in July 2012 for inciting hatred between the Kikuyu ethnic group and the Luo community of Prime Minister Odinga shows the centrifugal potential of popular music.

It is commonplace to find people at marketplaces, in mammy-trucks, at funerals, eateries and so on discussing the lyrics of popular music. These discourses are pertinent as they act as feedbacks, that is, the closure of the circuit between sender (popular musician) and receiver (Ghanaian) within the socio-cultural and communication networks of the Ghanaian macro-society. 


\section{Conclusion}

This paper has amply demonstrated that popular music discourses are important within the political, economic, psycho-social, and communication relations within the Ghanaian cultural environment. As indicated in the above discussion, it is possible to analyze socio-cultural change and psychological perceptions within the cultural matrix of any nation by the holistic study of popular music discourses. Further, the protean nature of the Ghanaian cultural environment has been dealt with as reflecting the discursive functionalities evoked in popular music. Popular music has, also, been set off as an autonomous field of media and communication worthy of research in Ghana. Furthermore, the individual and social dimensions of its functions and the communication relationships that exist between the systemic world and the traditional life world has been discussed.

It is relevant to also note that an analysis of the musical text has not been done since the discussion was restricted to the cultural environment and its discursive corollaries. But then, it is important to mention here that there could be a multiplicity of meanings and sign values in the text. This plethora of engendered meanings could be partially couched in the media text (here the popular music text) within the matrix of the cultural environment ( Real, M. 1989).

\section{References}

Akenoo, M. ( 2008, January 5). The Role of Music Artistes. The Ghanaian Times, p.11

Asante-Darko,N. \& Geest,D.V. S.(1983) Male Chauvinism: Men and women in Ghanaian highlife songs. In C. Oppong (Ed). Female and Male in West Africa (pp242-255). London, Allen and Unwin.

Burnett, R. (1990). Concentration and Diversity In the International Phonogram industry. Department of Journalism and Mass Communication, University of Gothenburg, Sweden.

Dominick, J. R. (2012). The Dynamics of Mass Communication: Media In Transition (12th Ed.). Boston, McGraw-Hill Education

Fiske, J. (2010). Introduction to Communication Studies (Studies in Culture \& Communication). London, Routledge.

Fornas, J. (1990). Popular Music and Youth Culture in Late Modernity.NordicomSweden, 1-2, 29-39.

Herna, H, Wiflihani,W., Hakim, I., Mukhlis, M., \& Suharyanto,S. (2020). "Therapeutic Music Creation Based on Soundscape of North Sumatra as a Media for Relaxation and the Covid-19 Pandemic". Budapest International Research and Critics Institute (BIRCI-Journal). Vol. 3, No. 4.

McQuail, D. (2010). Mass Communication Theory (6th Ed.). London, Sage.

Nketia, J. H. (1986). The Music of Africa. London, Victor Gollancz Ltd.

Oppong, C. (Ed.) (1983).Female and Male in West Africa. London, Allen and Unwin.

Putri, D.M., \& Marsella, E. (2020)." Folklore as Ethnic Embodiment Bias: Value Analysis on Karo Folklore”. Budapest International Research and Critics Institute (BIRCIJournal), Vol.3,No. 4.

Real, M. R. (1989). Super Media : A Cultural Studies Approach. London, Sage.

Reisman, D (1950). Listening to Popular Music. America Quarterly, 2,359-371. 